\title{
La iconografía chalchihuiteña en los grabados rupestres del valle de Guadiana, Durango
}

\author{
Chalchihuites Iconography in the Petroglyphs \\ of the Guadiana Valley, Durango \\ José Luis Punzo Díaz \\ INSTITUTO NACIONAL DE ANTROPOLOGÍA E HISTORIA, jose_punzo@inah.gob.mx
}

La iconografía producida por la cultura Chalchihuites ha sido poco trabajada de forma integral en sus diversas expresiones. Es así que el presente artículo busca analizar dos cuestiones principales, en primer lugar, definir el conjunto de grabados en las rocas que se han podido registrar en el valle de Guadiana, lugar central de la ocupación chalchihuiteña en Durango y, segundo, revisar la iconografía que se ha encontrado plasmada en cerámica chalchihuiteña y que, sostenemos, tiene una relación clara con los motivos grabados en la roca, creando así las bases para el estudio integral de las expresiones gráficas de estos grupos, en el extremo septentrional de Mesoamérica.

Palabras Clave: arqueología de Durango, Cultura Chalchihuites, iconografía, frontera norte de Mesoamérica.

There are few integral studies of the iconography produced by the Chalchihuites culture in its diverse expressions. In our research, therefore, we set out to analyze two main issues; first, to reach a definition of the petroglyph complex that is manifested in various sites around the Guadiana Valley, a central place for Chalchihuites culture in Durango; and, second, to relate the iconography present in Chalchihuites ceramics to those petroglyphs, which, we argue, are clearly interrelated, and so establish the bases for the integral study of the graphic expressions created by these groups along the northern frontier of Mesoamerica.

KEYwORDs: archaeology of Durango, Chalchihuites culture, iconography, northern frontier of Mesoamerica.

Fecha de recepción: 1 de julio de 2016 / Fecha de aceptación: 14 de febrero de 2017 / Fecha de versión definitiva: 14 de marzo de 2017

as representaciones rupestres en el valle de Guadiana apenas han sido estudiadas en un par de trabajos sistemáticos (Guevara 2003, Rincón 2013), por lo que todavía nos falta mu- 
cho para poder tratar de entender un estilo de representación que pudiéramos identificar como chalchihuiteño característico del valle de Guadiana. Es importante remarcar que es el periodo Chalchihuites en el valle de Guadiana, que va de los años 600 al 1350 d.C., el que ha sido más estudiado, centrándose especialmente en trabajos arqueológicos generales (Kelley 1971, 2002, Guevara 2003, Vidal 2011, Sandoval 2011, Punzo 2013) ha sido hasta hace poco, que se han realizado buenas investigaciones sobre la iconografía de estos habitantes mediante el análisis de sus grafismos plasmados en la cerámica (Rodríguez 2009, Ambriz 2013, Rangel 2014). Es en ese sentido que el presente trabajo trata de dar un recuento de los motivos rupestres grabados en la roca en cuatro de los sitios más importantes que se hallan en el valle: La Ferrería, El Arroyo de la Tigra, La Puerta de la Cantera, El Nayar y las Maravillas 6-el Nogal (Punzo et al., 2007), para con esto empezar a dar cuenta de un estilo de las representaciones grabadas en roca.

Antes de iniciar con la descripción y el análisis de los sitos antes mencionados, es importante decir que existen más lugares en el valle de Guadiana con manifestaciones rupestres. Primero, aunque ya fuera del valle propiamente dicho, se encuentra el sitio de la Cueva de Benjamín Aranda, cerca de Cacaria. Me detengo a comentar esto ya que se trata de un lugar muy particular donde se encuentran pinturas realizadas en tonos rojos y negros, la mayoría con motivos abstractos en forma de líneas y peines que recuerdan los descritos para otros lugares de Durango como la Cueva de la Garza, Piedra de Amolar o Cueva de las Mesas Pelonas y que se han asociado a expresiones prechalchihuiteñas relacionadas con el llamado estilo Chihuahua Abstracto Polícromo (Berrojalbiz, Hers y Punzo 2013), además de algunos motivos antropomorfos.

En segundo lugar, quiero comentar sobre otro sitio que he dejado fuera de la descripción y del análisis, el del Abrigo de la Mesa del Tunal, el cual presenta una serie de pinturas hechas con colores rojos que parecen seguir un estilo muy distinto al resto de los sitios y que por el momento no he podido asociar de ninguna forma a algún desarrollo cultural, dejándolo aun como una incógnita dentro de la historia del valle. 
El tercero se trata de la Cueva del Zapote, que se encuentra cerca de Santiago Bayacora y que contiene pinturas hechas en colores rojos principalmente y algunos blancos. Estas pinturas, aunque tienen particularidades específicas en las representaciones, también presentan similitudes importantes como lo son la representación de algunos antropomorfos esquemáticos con tocados similares a los de los petrograbados que vamos a analizar, además de la presencia de cuadretes y la representación esquemática de vulvas. Sin embargo, para fines de este artículo he decidido dejarlos de lado por el momento, ya que la técnica pictórica usada aquí y la de petrograbado tienen diferencias en los resultados en la ejecución que en este momento no pretendo analizar, aunque entiendo que lo más probable es que las pinturas de la Cueva del Zapote puedan formar parte del corpus chalchihuiteño que pretendo presentar.

\section{Los Sitios CON PETROgRabados DEL VALLE DE Guadiana}

\section{La Ferrería ${ }^{1}$}

El sitio arqueológico de la Ferrería es el de mayores dimensiones y complejidad en el valle de Guadiana. En éste se encuentran múltiples estructuras habitacionales ordenadas en su mayoría a través de patios y terrazas, así como la existencia de estructuras exclusivas para el uso ritual como los dos basamentos piramidales y la cancha de juego de pelota. No obstante, la Ferrería igualmente presenta una buena cantidad de grabados en las rocas diseminados por todo el cerro donde se encuentra el sitio arqueológico. Estos grafismos se encuentran distribuidos en nueve conjuntos (Punzo y Rincón 2006).

El conjunto 1 se localiza a aproximadamente unos $20 \mathrm{~m}$ del canal de riego orientando su cara grabada al norte. La roca donde se realizó el motivo presenta cierto pulido de la superficie como preparación previa.

Este conjunto 1 está conformado por un solo grafismo, el cual personifica a un antropomorfo sexuado - masculino- representado

${ }^{1}$ N 2649961, E 0535865, 1904 msnm. 
Figura I. Vista general de la zona arqueológica de la Ferrería

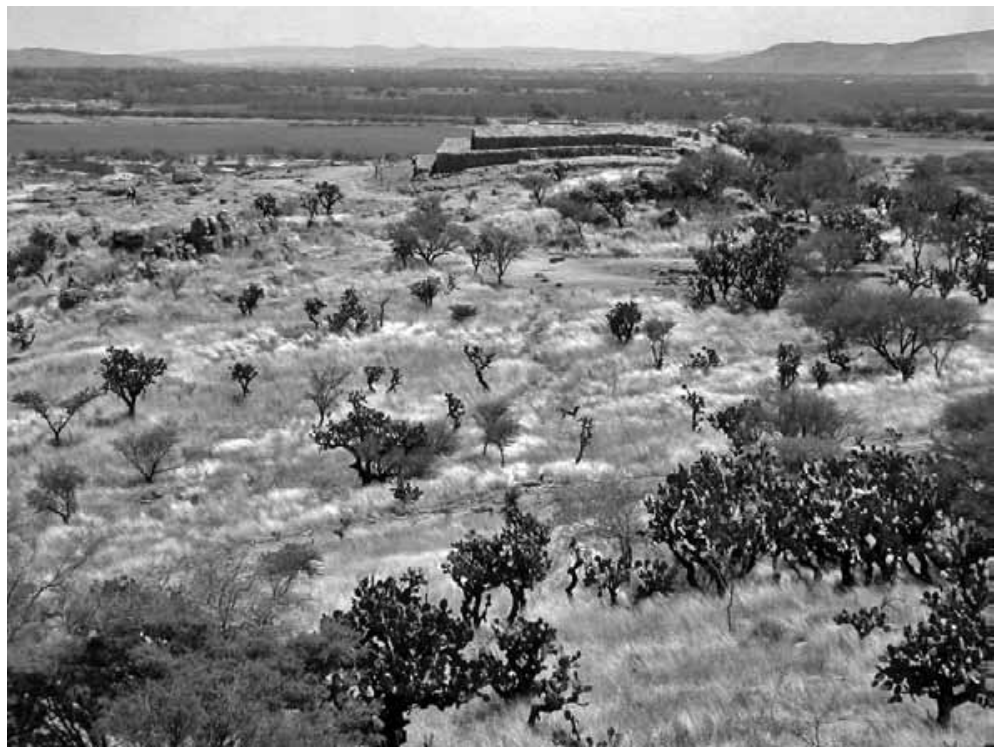

de frente, con sus extremidades superiores levantadas y extendidas a los costados con un ángulo recto en sus codos sobre la cabeza. Ésta presenta un par de trazos curvo-divergentes en su parte superior, a manera de tocado. El torso está representado con dos trazos paralelos y las extremidades inferiores se representaron flexionadas hacia los costados, en un ángulo recto. La realización del grabado se hizo mediante la técnica de percusión o picoteo.

El conjunto 2 se localiza en el punto donde inicia la pendiente del cerro por su flanco este. El grafismo se encuentra muy cercano de un conjunto de cuartos y una pequeńa escalinata, además de que justo frente a él se halla un pequeño círculo de piedras que pudiera ser una especie de altar. El bloque ígneo que fue usado para realizar el conjunto de grabados tiene una orientación hacia el este.

Este panel está compuesto por un diseño lineal, dos motivos zoomorfos y un antropomorfo que domina la escena. El diseño lineal se localiza en un extremo del panel y parece un poco fuera del resto del conjunto. El primer zoomorfo se localiza en la parte baja 
del panel, entre las extremidades inferiores del personaje. Este cuadrúpedo se encuentra representado de perfil relativo derecho. La cabeza presenta las dos orejas del animal separadas. El motivo se representó con las fauces entreabiertas. Llama la atención que no fue figurada la cola del animal. Junto a éste se encuentra un grabado abstracto que asemeja una letra $\mathrm{A}$.

El antropomorfo es el personaje principal del conjunto, se representa de frente ataviado con una especie de faldellín y sujetando en sus "manos" ciertos artefactos que más adelante describiremos. Las extremidades están formadas por un par de trazos rectos que sobresalen de los hombros y cadera del personaje, que le dan una apariencia de una X. En el extremo del brazo izquierdo apreciamos un trazo que pudiese representar algún tipo de herramienta. Entre tanto, el brazo derecho pareciera sujetar algún tipo de objeto ovoide ya muy borroso, tal vez un arco y flecha. La cabeza presenta una forma triangular y sobre ella sobresalen dos trazos curvo divergentes a manera de tocado.

Al lado de la extremidad inferior izquierda del personaje, registramos el segundo motivo zoomorfo representado de manera esquemática en perfil relativo. El cuadrúpedo, actualmente luce acéfalo, la representación de su "cola" se hizo mediante un trazo perpendicular.

La orientación del panel hacia el este, hace que este motivo reciba los rayos solares por la mañana. Esto es de capital importancia durante los equinoccios, ya que a través de estudios arqueoastronómicos en la zona hemos podido establecer que durante esa fecha este motivo está alineado con la jamba sureste de puerta este del patio hundido y a la escalinata de la Pirámide 1 . Se forma así una línea imaginaria entre estos elementos arquitectónicos, el conjunto 2 y el disco solar al amanecer tras la Sierra del Registro, en los equinoccios. Igualmente importante es destacar que desde la parte baja del cerro este fenómeno es observable, primero por la dimensión del conjunto que en su totalidad es de más de $2 \mathrm{~m}$, además de que seguramente en esa parte del pie del cerro se podían concentrar un gran número de personas (Punzo 2012).

El conjunto 3 de petrograbados se encuentra asociado a una estructura rectangular de dos cuerpos, conocida como "pequeño recinto" (Guevara 2003). Los grafismos se encuentran en la cara oeste 
de la roca. Se aprecian cinco motivos en este conjunto, todos asexuados: dos antropomorfos, uno de ellos incompleto y tres zoomorfos, uno de ellos también incompleto.

$\mathrm{El}$ antropomorfo completo fue grabado de frente con sus brazos extendidos hacia abajo en un ángulo de $45^{\circ}$. La cabeza tiene la forma de un triángulo invertido y las piernas están representadas por un par de líneas abiertas en un ángulo de $45^{\circ}$. Este motivo está unido a uno de los zoomorfos por el brazo izquierdo del antropomorfo $\mathrm{y}$ una de las patas traseras del animal, al igual que la cabeza del personaje se yuxtapone al trazo de la cola del mismo cuadrúpedo. En el segundo antropomorfo solamente se le representó el torso superior y los brazos levantados sobre la cabeza doblados en ángulo recto.

Los tres zoomorfos se encuentran representados en perfil relativo izquierdo dos y derecho el uno. Los cuadrúpedos presentan un tamaño desproporcionado de la cabeza con respecto al resto del cuerpo. Sus caras presentan la mandíbula entreabierta y las orejas puntiagudas y erguidas, los dos completos con su cola levantada. El zoomorfo que se halla incompleto solamente le fue representada la cabeza, torso y patas delanteras, aunque estas últimas parecen haber sido agregadas recientemente.

El conjunto 4 se encuentra ubicado al este de la Casa de Piso de Piedra y se compone de seis morteros fijos, y una vulva asociada, distribuidos en tres rocas. Únicamente registramos una preparación previa del soporte en la roca donde se localizó la vulva. Los morteros fueron realizados con la técnica de picoteado, mientras que la vulva fue manufacturada por medio de desgaste o pulido de la roca.

El conjunto 5 se trata de dos de petrograbados y un mortero fijo que se localizan en la esquina sureste de la Casa del Piso de Piedra. El mortero destaca de todos los registrados hasta el momento en el valle de Guadiana por ser el único que presenta un reborde de $4 \mathrm{~cm}$ de espesor, además de un diámetro interior de $33 \mathrm{~cm}$ y una profundidad de $11 \mathrm{~cm}$. Justo al centro del mortero, en la roca vertical, se localiza el primer diseño antropomorfo. Se trata de un personaje esquemático representado de frente, con brazos y piernas doblados en ángulo recto hacia abajo, acéfalo y en su lugar se halla el mortero que ya se describió. Sin embargo, este grabado, seguramente en épo- 
cas posteriores, fue remarcado transformándolo en una cruz y el calvario, seguramente con la intención de sacralizarlo mediante este símbolo cristiano. El segundo grabado es una cruz muy deteriorada que pudo ser parte de otro antropomorfo esquemático hoy invisible.

El conjunto 6 de grabados se ubica entre la Pirámide 1 y la cancha de juego de pelota. En éste se encuentra un grupo de rocas que fueron colocadas de forma circular, existen tres profusamente grabadas y una cuarta un poco separada, en éstas podemos observar un pulido burdo para preparar la superficie de grabado.

El conjunto 6 está compuesto por más de 20 vulvas grabadas tanto de formas redondeadas como cuadrangulares, además de dos líneas paralelas perpendiculares similares a una L inversa y acostada, las cuales dan la impresión de unirse en sus extremos y un par de elementos redondeados que se salen del canon de factura de las vulvas. Sobre estas grafías se puede ver una tipología e interpretación detallada en el trabajo de la arqueóloga Sahira Rincón (2013).

En el conjunto 7 agrupamos un par de representaciones femeninas localizadas al suroeste de las Estructuras Circulares, en la porción suroeste del sitio. Estas dos representaciones femeninas fueron grabadas mediante incisiones indirectas sobre una superficie horizontal sin preparación previa. Una presenta una forma triangular y la otra ovalada.

En la parte posterior de la Casa de Piso de Piedra, se localizó otro grabado vulvar que denominamos conjunto 8. Ésta presenta un diseño cuadrado y se encuentra grabado toscamente sobre una superficie inclinada, la cual se orienta hacia el norte.

El conjunto 9 es un diseño abstracto de fino trazo y es uno de los grafismos más complejos registrados. Consiste en una bella espiral compuesta, que se envuelve en dos giros hacia la izquierda, y de la que salen a su vez otras tres prolongaciones curvas en diferentes direcciones. De estas tres, las dos que se ubican en la parte superior giran en la misma hacia la derecha, mientras que la que se ubica en la porción inferior del grafismo gira a la izquierda. El diámetro de la espiral central es de $20 \mathrm{~cm}$ y cabe señalar que este original diseño se encuentra grabado por incisión indirecta sobre un soporte totalmente vertical, el cual mira hacia el este. 


\section{Arroyo de la Tigra ${ }^{2}$}

Este sitio se encuentra en la cuenca del río Santiago Bayacora, en un reliz en la márgen norte cercano al arroyo de la Tigra, justo a la entrada del cañón, del mismo nombre (Punzo et al., 2007). Se trata de un frente rocoso de riolita que va conformando el cañón y que en este punto mide de altura en promedio $10 \mathrm{~m}$. Ahí a $4 \mathrm{~m}$ de altura se hace un escalón natural de $1 \mathrm{~m}$ de ancho donde arranca el muro que contienen múltiples petrograbados en un frente de aproximadamente $10 \mathrm{~m}$, que da su cara de forma general al sur, el cual se encuentra dividido naturalmente por distintas fracturas que nos sirvieron para poder partirlo en seis paneles que contienen 20 grabados. Se trata de uno de los sitios de petrograbados más bellos y conservados del valle de Guadiana.

De manera general, los grabados los dividimos a su vez en geométricos, lineales (zigzag, grecas, ondulantes-ochos), antropomorfos (completos, de cabeza, manos grabadas) y abstractos.

La descripción de los paneles será de este a oeste. En el Panel 1 únicamente registramos un grabado geométrico compuesto por un cuadrado de $63 \mathrm{~cm}$ de lado sin ninguna decoración en su interior.

En el Panel 2, sólo se localiza el posible grabado de una mano izquierda de la que sólo se reconocen cuatro dedos.

El Panel 3 presenta un largo diseño compuesto por un par de líneas zigzagueantes que se entrecruzan. En la parte inferior cercano al diseño en zigzag encontramos un grabado lineal abstracto.

El Panel 4 llama la atención ya que encontramos solamente antropomorfos. El motivo inferior consiste en un diseńo compuesto por antropomorfo esquemático sexuado representado de frente con las piernas separadas y rodillas dobladas en un ángulo recto, en éste sus brazos, que se encuentran en posición flexionada hacia abajo, se prolongan formando un cuadrete que lo enmarca. Por ello, sólo la cabeza parece estar fuera de este cuadrete. En este mismo panel se halla un segundo antropomorfo esquemático, asexuado, presenta la particularidad de haber sido colocado de manera des-

${ }^{2}$ E 544142, N 2641960, 1904 msnm. 
FIgura 2. Vista general del sitio de Arroyo de la Tigra

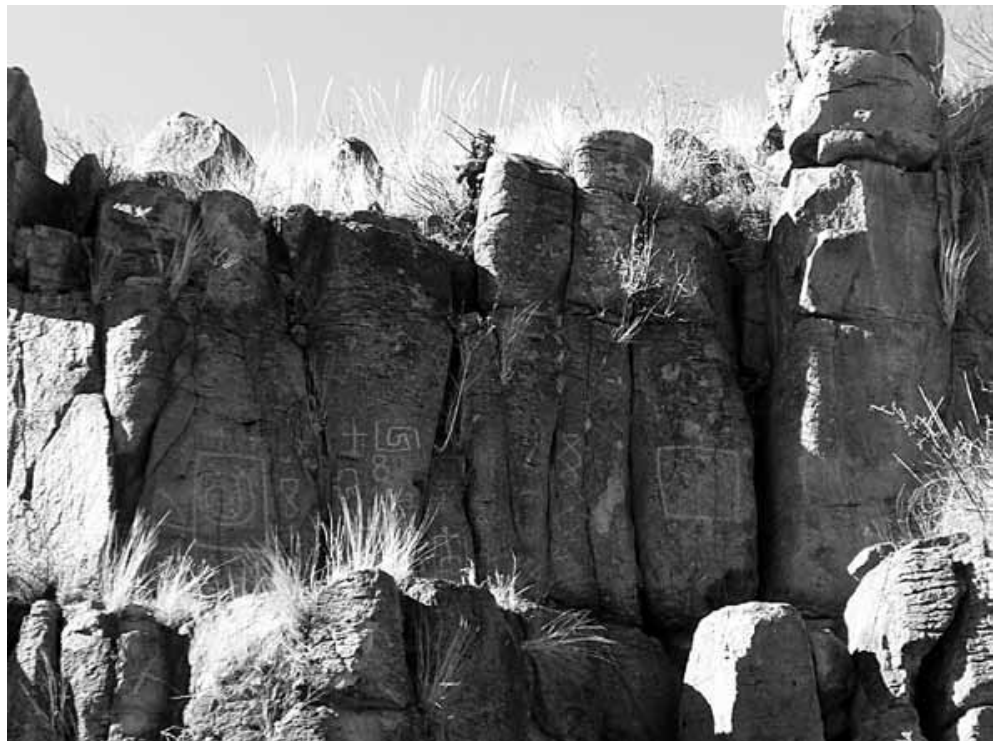

cendente, es decir, de cabeza con los brazos extendidos sobre su cabeza y las piernas rectas. Parece que este motivo fue representado de manera acéfala. Aspecto que, como veremos, se repite en varios sitios.

El Panel 5 presenta en su mayoría motivos abstractos, lineales y tres posibles antropomorfos esquematizados. Destaca una greca-espiral de forma cuadrangular, redondeada en sus vértices, su dirección envolvente gira hacia la derecha. Ésta es muy similar a motivos que encontramos en la cerámica chalchihuiteña. El primer antropomorfo esquematizado presenta su extremidad superior derecha extendida hacia arriba, mientras que el brazo izquierdo se representó hacia abajo en un ángulo recto. No presenta detalle en su cabeza y sus extremidades inferiores no parecen haber sido representadas. Se puede observar un diseño ondulante en forma de ocho, así como otro de forma semicircular con dos trazos que sobresalen en la parte de abajo, así como otro más al frente que pudiera ser tal vez un zoomorfo. Igualmente se puede ver un pequeño antropomorfo esquematizado representado de frente muy deteriorado. 
Destaca en este panel un motivo que pudiera ser un zoomorfo esquemático representado en perfil relativo y no presenta una clara unión de su torso con el elemento circular localizado en su parte inferior. Me parece que para este elemento podríamos pensar que se trata de la representación de un ave, animales muy representados en la iconografía chalchihuiteña de forma similar (Rangel 2014).

El Panel 6 se caracteriza por un cuadrete decorado en su parte central, asociado a varios motivos abstractos y geométricos. Éste está compuesto por un cuadrete de 95 por $60 \mathrm{~cm}$ profusamente decorado tanto en su interior como en el exterior. En la parte inferior del cuadrete se aprecian cuatro líneas casi paralelas que salen en posición vertical. Las tres primeras líneas son más cortas que la cuarta. En la porción superior del grafismo se aprecia un par de motivos cruciformes. Como decorado interior se hallan dos elementos principales, el primero es un trazo lineal dispuesto de manera vertical localizado en la esquina superior derecha mientras que el diseño central que decora al cuadrete consiste en una espiral de tres vueltas que gira a la derecha. En la parte inferior oeste del panel encontramos un medio círculo limitado por dos líneas perpendiculares que lo hacen parecer la representación de un arco y una flecha. Finalmente, en la parte baja de todo el conjunto se encuentra un círculo completo del que sobresale una línea.

\section{Puerta de la Cantera ${ }^{3}$}

Este sitio con abundantes manifestaciones gráfico rupestres se localiza sobre el lecho del arroyo intermitente que divide a la mitad la comunidad de Puerta de la Cantera en una extensión de casi $80 \mathrm{~m}$ de largo, por el ancho del arroyo que llega a tener $15 \mathrm{~m}$ (Punzo et al. 2007). Cabe seńalar que estos petrograbados fueron registrados en 1987 por Jesús Lazalde (1987).

Se dividieron los casi 100 grabados en diez paneles y seis elementos aislados. La gran mayoría de los grabados presentan una técnica 
Figura 3. Vista general del arroyo de la Puerta de la Cantera

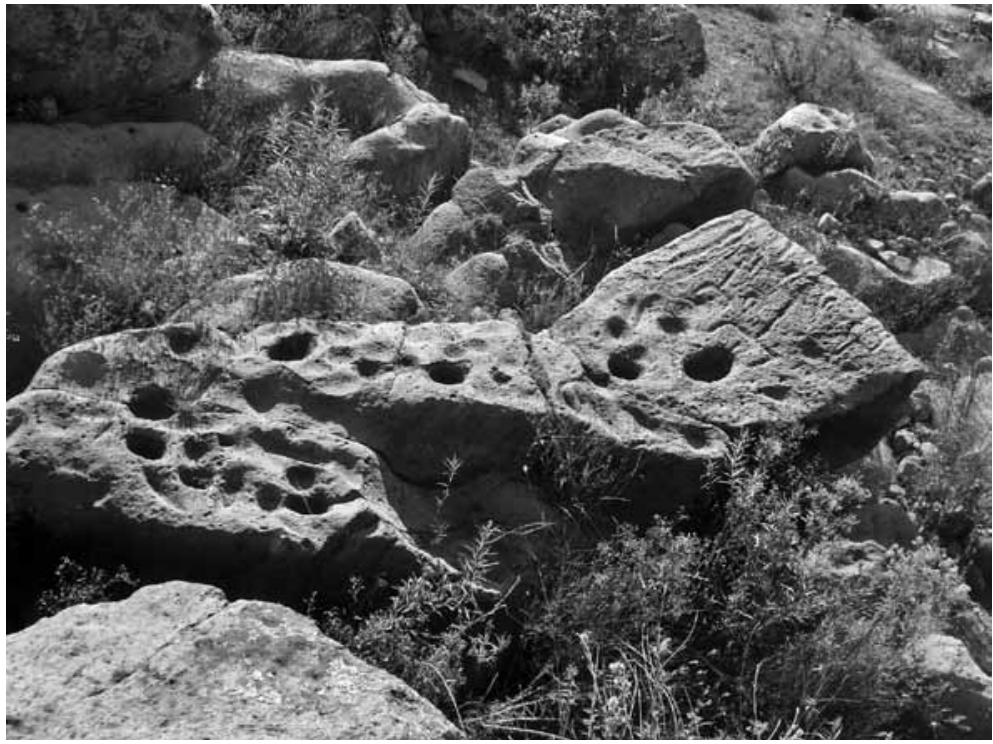

de incisión indirecta o picoteado, y algunos motivos fueron realizados por desgaste o abrasión.

El Panel 1 es el que más ha llamado la atención de este sitio, ya que se ubica en el centro del arroyo y es posible apreciar sus grabados a la distancia. Éste presenta dos de sus caras grabadas. En su primer lado encontramos tres motivos cruciformes realizados por picoteado o incisión indirecta. El motivo cruciforme central presenta mayores dimensiones y pudiera tratarse de un antropomorfo muy esquemático.

El segundo lado del Panel 1 presenta la mayor abundancia de motivos, además de cuencos interconectados por delgados canalitos. En primer lugar se identifican claramente tres antropomorfos de trazo esquemático representados de frente que son los que destacan por su tamaño que es de más de $80 \mathrm{~cm}$ de largo. Dos de ellos presentan los brazos levantados en ángulo recto hacia arriba y las piernas dobladas por la rodilla. El tercer antropomorfo no presenta extremidades superiores solamente las piernas dobladas al igual que 
los anteriores. Las cabezas de los tres son redondeadas aunque uno de ellos pareciera tener una forma más trapezoidal. En el motivo central se pueden ver ciertos rasgos del rostro, que corresponderían al ojo derecho y a un sencillo esbozo de una boca un tanto sonriente, aunque nos parece que éstos son adiciones posteriores, ya que no existen tales atributos en otros grabados que hayamos registrado. Estos tres antropomorfos descritos presentan la misma técnica de manufactura que consiste en incisiones indirectas o picoteadas.

Especialmente en el motivo central llama la atención que una vulva de $15 \mathrm{~cm}$ de diámetro que se encuentra claramente representada entre las extremidades inferiores del motivo. La vulva del personaje se encuentra íntimamente asociada a un cuenco alargado. De la misma manera aunque no de forma tan directa se aprecian otro par de vulvas que se encuentran entre los dos antropomorfos completos y una de ellas se asocia igualmente a un cuenco. En el tercer antropomorfo, aunque muy levemente, se puede apreciar un pequeño grabado entre sus piernas posiblemente un falo. Aunque muy intemperados por la acción del agua, se pueden ver algunas líneas y círculos que se distribuyen por toda la roca así como 22 cuencos que de distintas maneras se van contactando entre sí, muchos de ellos por medio de pequeños canales grabados en la roca, algunos de manera muy somera. Esta escena se localiza en el centro del arroyo, y se halla cubierta de agua, durante la época de lluvias, todos los motivos se encuentran sexuados existiendo una fuerte relación entre las vulvas, los cuencos y ligeros canales que parecen interconectarlos.

El Panel 2 solamente está formado por un motivo antropomorfo esquemático representado de frente, en pésimo estado de conservación.

Por otra parte, el Panel 3 se encuentra decorado con aproximadamente 50 cuencos circulares y ovalados de diámetros y medias variables entre: 5 y $30 \mathrm{~cm}$. En uno de sus costados se aprecia un diseño abstracto, el cual consiste en varias líneas perpendiculares realizadas por picoteado o incisión indirecta. Todas las caras de esta roca presentan grabados, así en la cara norte apenas se distingue de manera parcial el trazo de un antropomorfo esquemático del que sólo se conserva el torso alargado y sus extremidades inferiores abiertas con las rodillas 
dobladas en ángulo recto. A pocos centímetros, se aprecian un par de líneas zigzagueantes dispuestas de manera vertical, que forman un rombo y un ángulo abierto. En la cara oeste se distinguen trazos zigzagueantes muy similares a los hallados en esta misma roca. Consiste en dos líneas dispuestas de manera vertical, que forman un rombo.

En el Panel 4 se encuentra representada una de las más interesantes escenas registradas en este sitio, la cual fue realizada mediante la técnica de picoteado o incisión indirecta. Se representaron dos personajes de frente con sus extremidades extendidas hacia los costados. Estos dos antropomorfos asemejan estar tomados de las manos. El primer personaje pareciera portar una especie de faldellín muy definido realizado al aprovechar una oquedad y presenta un tocado formado por dos elementos. El segundo personaje pareciera tener un trazo más fino, sus manos más alargadas, un faldellín menos definido y sus extremidades inferiores más cortas que el anterior. Da la sensación que su mano izquierda se une con la oreja derecha del primer zoomorfo. Éste presenta un tocado distinto, al parecer, de forma triangular a los lados de la cabeza. En este Panel 4 se aprecian dos zoomorfos presentados en perfil. El primero de estos cuadrúpedos, es un poco más pequeño que el segundo. Llama la atención que de las colas de ambos zoomorfos, llegan hasta la parte superior de la roca donde se entrelazan y finalmente se unen, además se puede apreciar a un lado una vulva triangular. Un poco alejado se puede reconocer un tercer antropomorfo representado de frente con sus extremidades separadas y sus brazos levantados, de dimensiones más reducidas.

El Panel 5 contiene grabados en dos de sus caras, la primera solamente presenta dos pequeños motivos antropomorfos incompletos, difícilmente reconocibles. Es, sin embargo, la cara norte en la que se pueden apreciar cinco motivos antropomorfos sexuados y asexuados que se encuentran grabados por incisión indirecta, ésta más profunda que la mayoría de los casos. En estos destacan primeramente dos antropomorfos completos, que tienen los brazos extendidos sobre sus cabezas y piernas estiradas, ambos parecieran tener cierto movimiento en su representación. Existen otros dos motivos grabados con la misma técnica que se aprecian incompletos, ya que limitan con el piso donde se encuentra clavada la roca, sin embargo, es 
posible que continúen, pero se tendría que excavar en el lugar. En uno de éstos se puede apreciar que posiblemente tiene un motivo vulvar entre sus piernas, no obstante, es necesario excavar para confirmarlo. Finalmente, el quinto antropomorfo se realizó con una técnica de grabado mucho más somera y se trata de un personaje esquemático con brazos y piernas abiertas hacia abajo.

El Panel 6 presenta varios cuencos interconectados por canales, así como una cruz grabada en una de sus caras. En otra cara de la misma roca, se encuentra un posible insecto de seis patas y dos antenas, diseño muy inusual. Además de este singular grabado, encontramos 12 representaciones de vulvas: siete circulares, cuatro cuadradas y una ovalada.

En el Panel 7 solamente se aprecian ciertos trazos lineales muy intemperizados. También se encuentran un par de cuencos con acanaladuras en sus extremos. Justo en el límite oeste identificamos una pequeńa vulva ovalada realizada con un burdo picoteado. En la otra cara de la roca hallamos un antropomorfo esquemático de tamańo reducido apenas visible. Se encuentra figurado de frente con los brazos extendidos y pareciera portar cierto artefacto alargado. Asociado al antropomorfo distinguimos el trazo de un zoomorfo en perfil con dimensiones proporcionales al motivo anterior.

En la parte superior de la roca del Panel 8 se encuentra un cuenco ovalado asociado a una pequeña vulva circular. En la cara vertical se encuentran tres grafismos de trazo esquemático realizados por abrasión o desgaste. El personaje de mayor dimension es un antropomorfo de $70 \mathrm{~cm}$ de largo. Este personaje se encuentra representado de frente con las extremidades inferiores juntas y pies que apuntan en direcciones opuestas. Su torso alargado presenta el mayor grosor del trazo. En tanto que los brazos se representaron hacia arriba con trazos rectos en un ángulo recto sobre la cabeza y en la cabeza pareciera llevar un tocado lineal sencillo. Junto a éste se grabó un cuadrúpedo representado en perfil izquierdo con cuello alargado, cabeza levantada y cola. A un lado de ambas figuras se puede apreciar un trazo esquemático que pudiera tratarse de un torso y cabeza con tocado triangular a los lados, esta figura es similar a otras encontradas en el valle de Guadiana, sólo que ésta en pintura en el sitio de la Cueva del Zapote. 
El Panel 9 presenta grafismos en sólo una de sus caras. Se aprecian ciertos trazos verticales realizados por picoteado o incisión indirecta y se encuentran asociados a un antropomorfo esquemático lineal, acaso en actitud descendente, similar al registrado en el Arroyo de la Tigra. También identificamos un cuadrado apenas delineado sin decoración en su interior.

Finalmente, el Panel 10 sólo presenta grafismos en una de sus caras, que fueron realizados por picoteado o incisión indirecta. Distinguimos un pequeño antropomorfo en la parte media baja de la roca que fue personificado de frente con los brazos hacia arriba en un ángulo recto. Su cabeza es circular y apenas se conservan algunos restos de trazo de la pierna izquierda. Un poco más arriba, se distingue el trazo de un posible asterisco o motivo lineal, que acaso pudiera semejarse a un zoomorfo incompleto.

Por otra parte, en el sitio de la Puerta de la Cantera, se encuentran seis elementos aislados. El primero se trata de un trazo lineal en forma de $\mathrm{Z}$ de $25 \mathrm{~cm}$ de alto. El segundo es un cuadrete que se localiza entre el panel 3 y el 9, este motivo geométrico presenta un decorado zigzagueante en su interior. El tercero es un diseńo elaborado por un burdo picoteado o incisión indirecta de una mano derecha. El cuarto es un zig-zag que nos sugiere la representación de una serpiente que va corriente arriba a la que se le puede distinguir su cabeza en forma de rombo, de la que salen un par de líneas, acaso su lengua bífida. La quinta se trata de una vulva de forma ovalada que se localiza en la porción oeste del sitio. Finalmente, el último elemento aislado se trata de un personaje del cual sólo se conserva el torso y cabeza, éste presenta los brazos levantados sobre la cabeza y un tocado de dos trazos curvo divergentes a manera de antenas.

\section{El Nayar ${ }^{4}$}

Éste es uno de los sitios arqueológicos más importantes del valle de Guadiana y donde a través de excavaciones arqueológicas hemos podido establecer que tuvo una ocupación previa al periodo chal-

${ }^{4}$ E 529625, N 2648890, 1920 msnm. 
chihuiteño, para luego ser una de las primeras aldeas que recibió ya la influencia Chalchihuites. En este sitio, hemos localizado entierros con ofrendas cerámicas de los primeros momentos de la fase Ayala hacia el año 600 d.C. En su cumbre existen una gran cantidad de cuartos y patios que lo ordenan. Sin embargo, de manera aislada en las faldas del cerro hemos encontrado dos petrograbados.

El primero se trata de un zoomorfo representado en perfil relativo izquierdo que se halla incompleto, solamente le fue grabado, torso y patas sin cabeza, destacan la cola que parece larga y recta, tal vez representan a un felino. El segundo es muy relevante, ya que se trata de un antropomorfo grabado profundo y ancho, similar a algunos del sitio de Puerta de la Cantera. Se trata de un personaje cuyo cuerpo es una simple línea y parece no tener una diferenciación en sus piernas. Los brazos los tiene separados del cuerpo a los lados, lo que parece importante es que sobre la cabeza presenta un tocado hecho mediante una sola línea, detalle que se repite en la Puerta de la Cantera.

\section{Los Nogales-Las Maravillas de Abajo $6^{5}$}

Este sitio fue registrado cercano al cauce del río Santiago Bayacora. Los petrograbados son poco visibles a primera vista a excepción de algunos de los elementos mayores que han sido muy remarcados (Punzo et al., 2007). Estos grabados se dispersan en la pared rocosa por aproximadamente $100 \mathrm{~m}$, el frente rocoso tiene una orientación hacia el oeste. Debido al errático patrón de ubicación de los grabados así como al alto grado de destrucción antrópica, hemos decidido dividir temporalmente la descripción de los vestigios rupestres por conjuntos y en algunos casos como elementos aislados.

El primer grabado aislado se localiza en el límite noreste del sitio, justo a ras del piso. Se trata de un motivo geométrico compuesto por tres cuerpos redondeados. El segundo grabado parece representar una especie de escudo, su diseño es muy elaborado y consiste en un círculo de $53 \mathrm{~cm}$ de diámetro, cuyo interior está decorado por

${ }^{5}$ E 535623, N 2641122, 1904 msnm. 
Figura 4. Vista general del sitio de MAV 6 Los Nogales

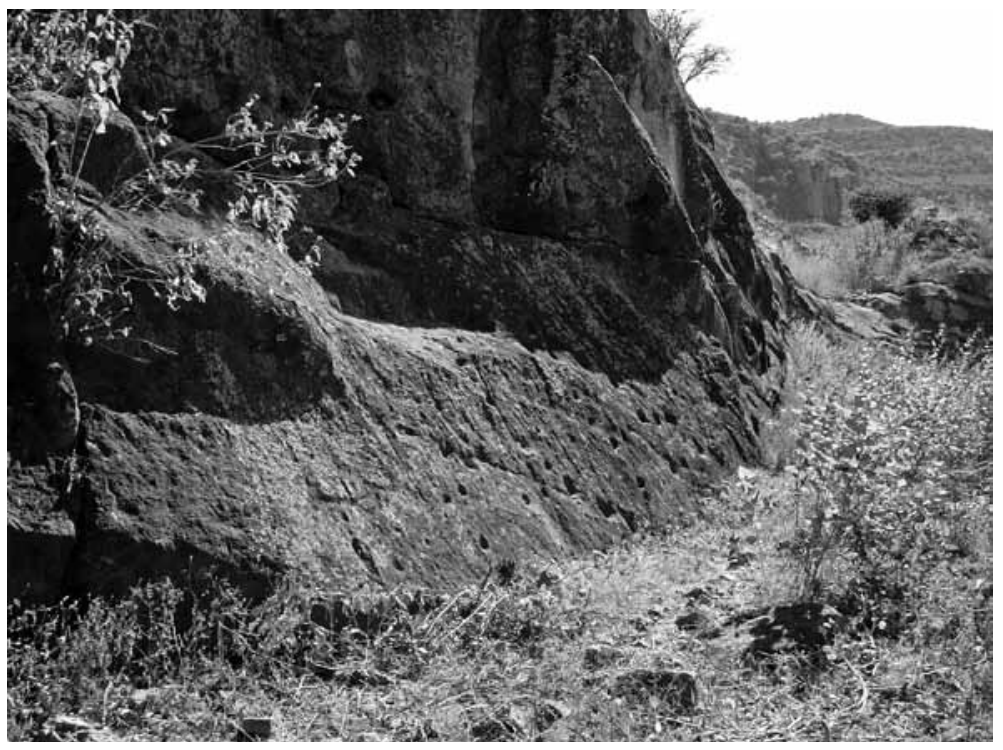

dos líneas perpendiculares. En la parte inferior del grafismo se distinguen 12 líneas que pudieran semejarse a plumas.

El tercer motivo aislado se localiza hacia el centro del sitio y consiste en un posible antropomorfo incompleto sexuado representado de frente, del cual apenas se distinguen sus extremidades inferiores y su falo. Muy cerca, se localiza el cuarto elemento aislado el cual consiste en un diseño antropomorfo dispuesto de frente, con sus extremidades inferiores separadas y con sus rodillas dobladas en un ángulo recto y acéfalo. El brazo derecho se encuentra doblado de manera envolvente en tres trazos lineales hacia abajo, y su diseño termina con un corto trazo vertical. Su brazo izquierdo, también delineado de manera envolvente, termina entonces con un corto trazo perpendicular que lo une a la rodilla izquierda. Los últimos dos motivos aislados se localizan en la parte sur del sitio, consisten en representaciones de vulvas una circular y la otra cuadrada.

En lo que se refiere a los conjuntos tenemos que el primero de ellos hacia su parte inferior, encontramos 36 pocitos circulares y 
ovalados dispersos de manera homogénea. El único grabado de morfología naturalista apreciable en este conjunto, es un motivo antropomorfo representado de cabeza y del que sólo se conservan sus extremidades inferiores y una parte de su tronco, muy similar a lo encontrado en el sitio de Arroyo de la Tigra y en la Puerta de la Cantera. En la parte superior del conjunto encontramos dos representaciones vulvares y numerosos cuadretes decorados de aproximadamente $30 \mathrm{~cm}$ de lado. El primer cuadrete tiene como decorado interior, una línea diagonal. El segundo cuadrete tiene un decorado interior que consiste en dos líneas diagonales, que semejan una $\mathrm{X}$ interior. A un par de metros, existe un tercer cuadrete, uno de los más ricamente decorados en este conjunto, su decorado interior es de naturaleza abstracta en donde en su parte inferior se aprecia un semicírculo decorado con un par de largas líneas curvas, y fuera de éste, encontramos un pequeño ovalo delineado. En cambio, en la parte superior del cuadrete encontramos un largo trazo horizontal del que salen seis líneas radiales. Sólo tres de ellas parecen cerrarse en su parte superior. A un par de centímetros abajo del tercer cuadrete, encontramos las dos vulvas de forma redondeada. Hacia la parte sur de este conjunto encontramos otros tres cuadretes decorados de diferentes dimensiones, se aprecian los decorados lineales y con motivos antropomorfos de los mismos

El segundo conjunto de grafismos se localiza en la parte sur del sitio del Nogal. Este panel presenta, igual que el primer conjunto, numerosas oquedades cóncavas en su superficie, las cuales, en este caso, se concentran en la porción central. En este conjunto encontramos un par de cruces y cinco cuadretes.

El primer cuadrete mide casi $20 \mathrm{~cm}$ de lado y se encuentra muy bien conservado. Su decorado interior está compuesto por dos líneas diagonales intersecadas en su parte central, que semejan una X.

El segundo cuadrete mide 42 por $34 \mathrm{~cm}$. Su decorado consiste en un diseño en zigzag, el cual forma dos pequeños rombos que se ubican en la parte superior derecha del cuadrete.

El resto de los cuadretes se ubican en la parte baja del soporte, uno tras otro en dirección al sur. El tercer cuadrete mide 70 por 32 $\mathrm{cm}$ y presenta un antropomorfo de menores dimensiones en su in- 
terior, que se encuentra representado de frente con todas sus extremidades extendidas y su cabeza fue representada con un triángulo equilátero invertido.

El cuarto cuadrete realizado por incisión indirecta incluye un diseño abstracto que nos pudiese sugerir un motivo zoomorfo profundamente grabado. A mi parecer se trata de un ave por su pico y alas y es similar en cierta medida a uno de los grabados registrados en el Arroyo de la Tigra.

El último de los cuadretes presenta en su interior un antropomorfo esquemático figurado de frente con sus extremidades inferiores dobladas en ángulo recto, acéfalo y con sexo masculino.

\section{ELEMENTOS QUE FORMAN EL COMPLEJO ICONOGRÁFICO DE PETROGRABADOS CHALCHIHUITEÑOS EN EL VALLE DE Guadiana}

Gracias al registro preciso que se ha venido realizando en estos sitios podemos comparar algunos de los diseños que hallamos grabados en la piedra con los motivos que los chalchihuiteños pintaron en sus cerámicas. Con esto lo que propongo es poder entonces fechar de manera indirecta los paneles de petrograbados y poder relacionarlos así con la ocupación chalchihuiteña en el valle de Guadiana (6001350 d.C.), desterrando la idea errónea que se ha plasmado en otras publicaciones, que infieren que los grabados realizados en sitios Chalchihuites como la Ferrería fueron hechos por grupos de cazadores recolectores, mucho tiempo antes (Guevara 2003).

Entonces para este fin comenzaré con los antropomorfos. En estos encontramos varios tipos, destacan los esquemáticos, tanto representados con las manos en alto como hacia abajo, eso sí todos con los brazos y piernas dobladas en ángulo casi recto. Sin pasar por alto los antropomorfos esquemáticos en posición descendente que hemos encontrado en tres de los sitios con petrograbados. Este tipo de antropomorfos completamente esquemáticos son muy poco representados en la cerámica Chalchihuites, solamente en el tardío tipo Nayar blanco sobre rojo (1150-1350 d.C.) he encontrado un par de éstos. Sin embargo, me parece que los que podemos relacio- 
Figura 5. Comparación entre antropomorfos representados en petrograbados y en cerámica
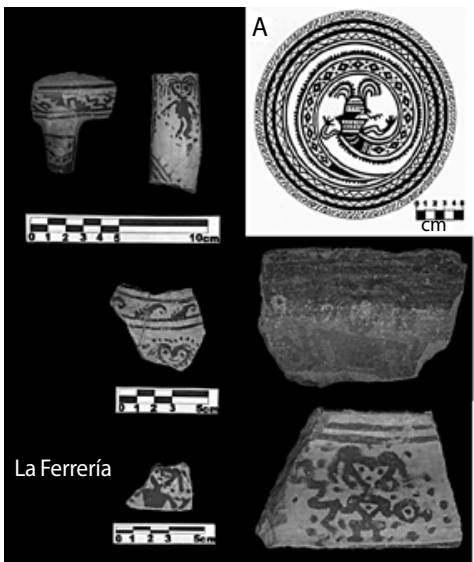
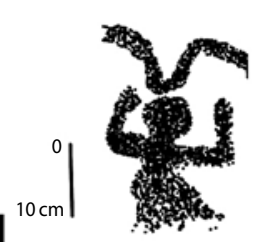

Puerta de la Cantera

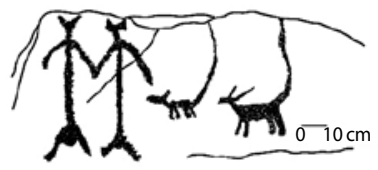

Puerta de la Cantera

nar más directamente son los grabados de los sitios de La Ferrería y Puerta de la Cantera, donde se encuentran representados éstos con un tocado realizado con dos trazos curvo divergentes, éstos, aunque mucho más detallados, los encontramos ampliamente representados en los tipos cerámicos chalchihuiteńos, Súchil, Amaro y Mercado, principalmente, característicos de la primera fase de ocupación Chalchihuites aproximadamente entre los años 600 y 800 d.C. (Punzo 2016). Es importante mencionar que existen otros tocados más simples de un solo trazo, como el localizado en la falda del cerro del Nayar, que igualmente me parece son parte de el mismo complejo aunque no estén tan representados en la cerámica Chalchihuites. Las representaciones de tocados triangulares han sido también relacionados con Chalchihuites por parte de Hers (Hers 2013, Berrojalbiz y Hers 2013) especialmente en el sitio del Salto del Perro en el valle de Guatimapé y se encuentran también presentes en el valle de Guadiana como ya se ha presentado.

Dentro de las expresiones antropomorfas también cabe mencionar la presencia de manos representadas tanto en la cerámica como en petrograbados con cuatro y cinco dedos. En este sentido en la cerámica destacan estas representaciones en tiestos de la Ferrería de 
FiguRa 6. Comparación entre manos representadas en petrograbados y en cerámica
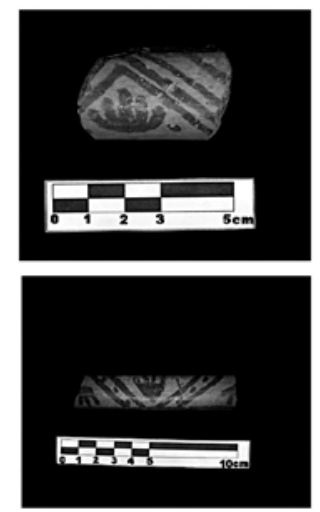

La Ferrería

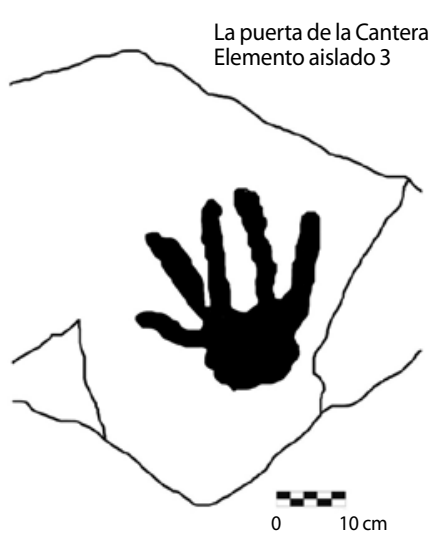

los tipos Refugio y Nevería, fechados entre los años 800 y 1,000 d.C., en fragmentos de asas de canasta. Estas manos las encontramos en los sitios de petrograbados de la Puerta de la Cantera y en el Arroyo de la Tigra.

Es muy importante incluir en este corpus las representaciones sexuales femeninas. Tema que ha trabajado ampliamente Sahira Rincón. Aquí simplemente quiero presentar además de los grabados de sitios como La Ferrería, Maravillas de Abajo 6-El Nogal y Puerta de la Cantera, una representación incisa en una figurilla que se localizó en el sitio del Nayar, la cual tiene marcado el sexo, siendo claramente similar a las representaciónes triangulares de estas que se han reportado.

Sobre los zoomorfos los que más destacán son los cuadrupedos. En este sentido y gracias a la identificación que ha realizado Diego Rangel (2014) podemos apreciar que la representación de dos orejas en muchos casos, así como de las cuatro patas, en forma de perfil relativo son constantes tanto en las representaciones cerámicas como en grabados. Aspecto que lo hace distinto a la propuesta que ha hecho Hers para la región norte chalchihuiteña en lo que ha llamado la comarca del venado (Berrojabiz y Hers 2013). 
Figura 7. Comparación entre vulvas representadas en petrograbados y en cerámica

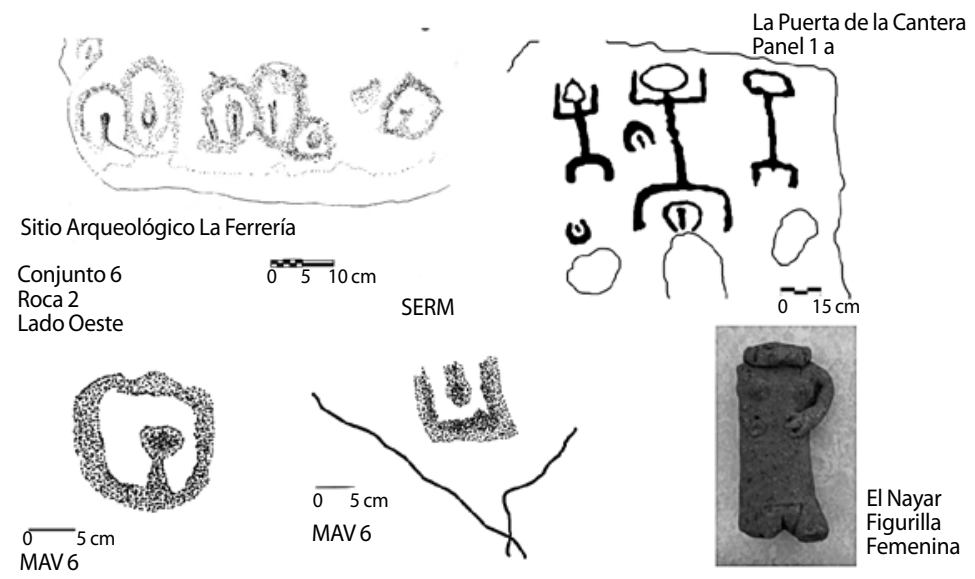

Entre las características importantes que destacar de los zoomorfos, y que se encuentran similitudes tanto en petrograbados como en cerámica, son el hocico, muchas veces cuadrado, y con las fauces entreabiertas, y por otra parte las colas rectas o curvas dependiendo muchas veces del tipo de animal que se buscó representar.

Dentro de los zoomorfos un motivo que llamó mi atención fue la representación de aves, aspecto que siempre habíamos pasado por alto. En este caso, también con una representación de perfil relativo podemos ver similitudes entre las abundantes representaciónes pintadas en cerámica en las asas de canasta y en el cuerpo de vasijas de los tipos Mercado, Refugio y Nevería, y las grabadas en los sitios de las Maravillas de Abajo 6-El Nogal y el Arroyo de la Tigra. Destaca la forma de los picos, las cabezas redondeadas y especialmente la forma curva usada para representar las alas.

Sobre los motivos abstractos siempre se ha destacado la relación entre los cuadretes, rellenos con distintos motivos y la cultura Chalchihuites (Forcano 2000; Hers 2013). En el valle de Guadiana, éstos los encontramos en los sitios de Puerta de la Cantera, Maravillas de Abajo 6-El Nogal y Arroyo de la Tigra. En este sentido solamente me gustaría agregar la relación que encuentro en el uso de esta grafía 
Figura 8. Comparación entre zoomorfos representados en petrograbados y en cerámica

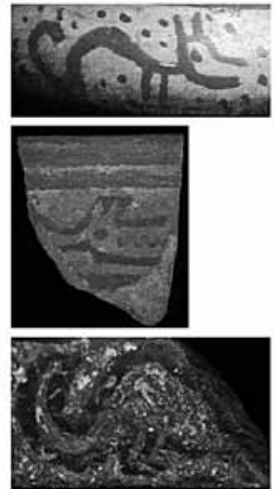

La Ferrería

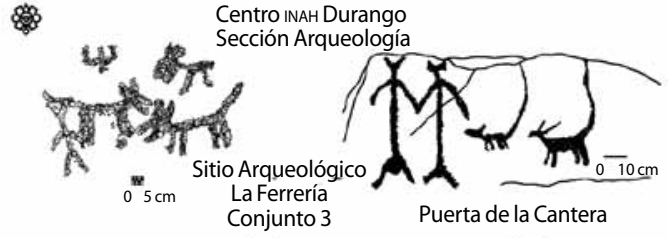

Sitio Arqueológico

La Ferrería

Conjunto 2

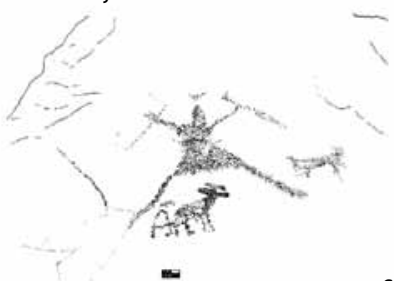

SERM

Figura 9. Comparación entre aves representadas en petrograbados y en cerámica

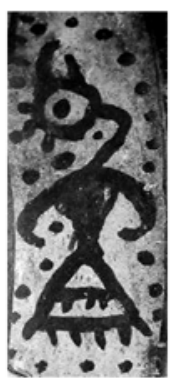

La Ferrería
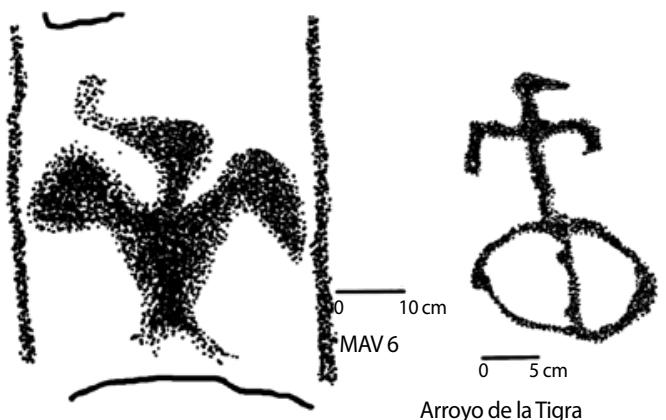

Arroyo de la Tigra

y las expresadas especialmente en la cerámica Nayar y en menor medida en la Otinapa, características del segundo periodo Chalchihuites, es decir, de entre los años 1,000 y 1,350 d.C.

Sobre los motivos abstractos podemos mencionar igualmente similitudes en el uso de dobles zig-zag formando diseńos de rombos como el del sitio de Arroyo de la Tigra, con los representados en va- 
Figura io. Comparación entre cuadretes representados en petrograbados y en cerámica

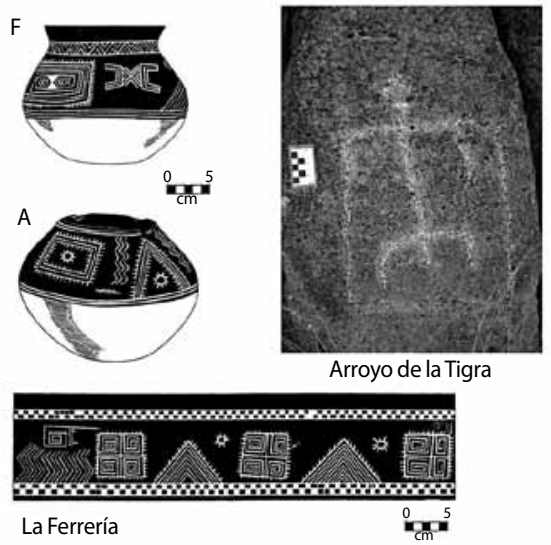

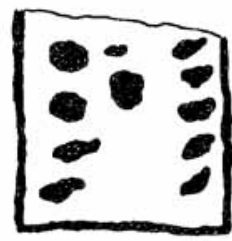

Puerta de la Cantera

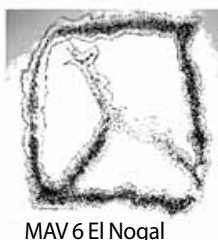

FIGURA I I. Comparación entre grecas representadas en petrograbados y en cerámica
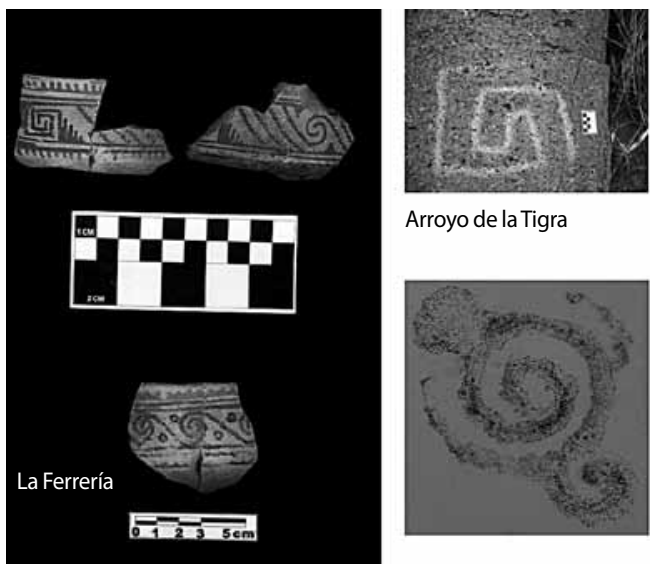

Arroyo de la Tigra
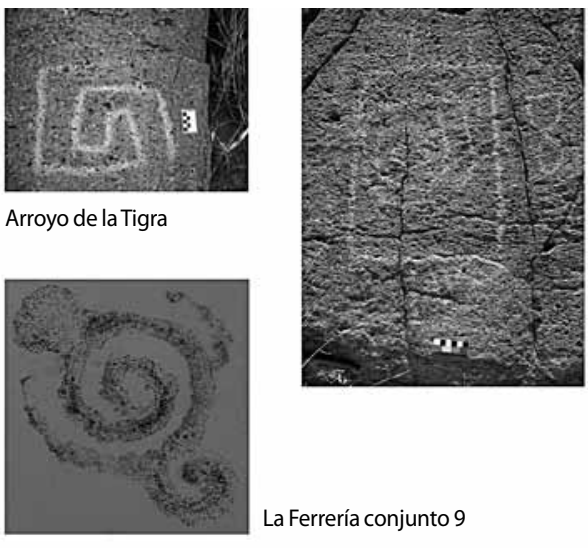

La Ferrería conjunto 9

rios tipos cerámicos chalchihuiteños, que van desde el Michililla incisos en rojo característico del principio del tiempo Chalchihuites, hasta en el Nayar al final de esta presencia. En ese mismo sentido y con un uso a todo lo largo de la secuencia chalchihuiteña en las 
Figura I2. Comparación entre zigzag representados en petrograbados y en cerámica

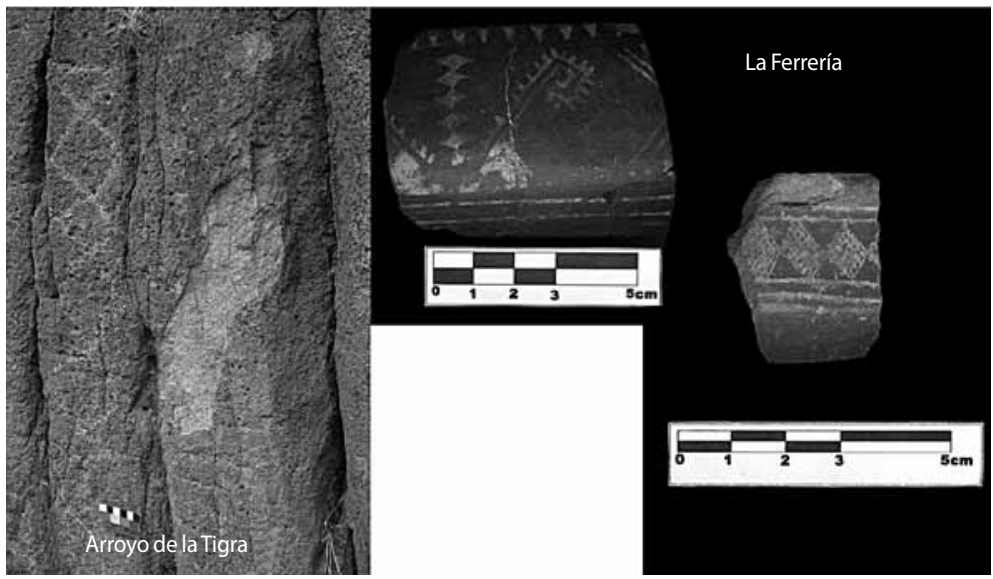

cerámicas, se representaron grecas de factura circular y cuadrada, similares a las halladas en los sitios con petrograbados La Ferrería, Arroyo de la Tigra y Maravillas de Abajo 6-El Nogal.

Simplemente para concluir quiero destacar que, si bien, ésta es una primera propuesta de un corpus iconográfico chalchihuiteño para el valle de Guadiana, este breve trabajo no es más que el comienzo para llegar a desarrollar estudios a profundidad en estos y otros sitios para poder entender esta manera cómo los antiguos habitantes de esta región de Durango festejaron, recordaron, perpetuaron y celebraron en su mundo a través de sus signos en las rocas.

\section{Agradecimientos}

Esta investigación forma parte del Proyecto Investigaciones Arqueológicas del Área Centro Oeste de Durango, el cual obtuvo financiamiento por parte del Instituto Nacional de Antropología e Historia y trabajó entre 2004 y 2012.

Este breve artículo incluye el trabajo de muchas personas que colaboraron a lo largo de los ańos en el Proyecto Arqueología y Paisaje del Área Oeste de Durango, pero quiero agradecer de forma 
especial a la arqueóloga Sahira Rincón Montero, quien estuvo a cargo del registro del arte rupestre en el proyecto.

\section{BIBLIOGRAFÍA}

Ambríz, Emmanuel. 2013. "La iconografía cerámica chalchihuiteña: análisis de las imágenes centrales en espiral”. Tesis de Licenciatura, Arqueología, Escuela Nacional de Antropología e Historia, México.

Berrojalbiz, Fernando y Marie-Areti Hers. 2013. "El alto Nazas. La Comarca del Venado". En Historia de Durango. Epoca antigua, ed. José Luis Punzo y Marie-Areti Hers. Durango: IIH, UJED.

Berrojalbiz, Fernando, Marie-Areti Hers y José Luis Punzo. 2013. "Arte rupestre arcaico". En Historia de Durango. Época antigua, ed. José Luis Punzo y Marie-Areti Hers. Durango: IIH, UJED.

ForCANo i Aparicio, Marta. 2000. "Las pinturas rupestres de Portero de Chaidez, Durango". En Nomadas y sedentarios en el Norte de México. Homenaje a Beatriz Braniff, ed. Marie-Areti Hers, José Luis Mirafuentes, Ma. de los Dolores Soto y Miguel Vallebueno. México: IIA, IIE, UNAM.

Guevara, Arturo. 2003. Ferrería. Conservación y estudio del sitio arqueológico. Durango: ICED.

Hers, Marie-Areti. 2013. "Durango y el antiguo camino de tierra adentro". En Historia de Durango. Época antigua, ed. José Luis Punzo y Marie-Areti Hers. Durango: IIH, UJED.

Kelley, Charles. 1971. "Archaeology of the Northen Frontier: Zacatecas and Durango". En Archaeology of Northen Mesoameri$c a$, ed. G. Ekholm e I. Bernal. Austin: University of Texas Press. 2002. "An Mesoamerican Colonization of Zacatecas-Durango: The Loma San Gabriel and Chalchihuites Cultures”. En Homenaje al Dr. John Charles Kelley, ed. M. T. Cabrero, Jaime Litvak y Peter Jiménez. México: IIA, UNAM.

Lazalde, Jesús. 1987. Durango Indígena. Durango: Museo de Historia, UJED. 
Punzo, José Luis. 2012. "Paisaje y petrograbados del sitio de la Ferrería, Durango, México". En Rock Art in the Americas: Mythology, Cosmogony and Rituals, ed. F. Fauconier y S. Lemetier. Londres: Archaeopress, British Archaeological Reports.

. 2013. "La población chalchihuiteña del Valle de Guadiana". En Historia de Durango. Época antigua, ed. José Luis Punzo y Marie-Areti Hers. Durango: IIH, UJED.

2016. "Revisando la cronología de la frontera Norte de Mesoamérica, estado de Durango". Arqueología Iberoamericana, vol. 29: 38-43.

Punzo, José Luis y Sahira Rincón. 2006. Informe Técnico Proyecto de Investigación y Conservación del Sitio Arqueológico La Ferrería, Durango 2006. México: Instituto Nacional de Antropología e Historia.

Punzo, José Luis, Sahira Rincón, David Arturo Muñiz y Diego Antonio Rangel. 2007. Informe Técnico del Proyecto Investigaciones Arqueológicas del Área Centro Oeste de Durango. Informe Técnico Temporada 2007. México: Instituto Nacional de Antropología e Historia.

Rangel, Diego Antonio. 2014. "Identificación de zoomorfos en los materiales arqueológicos de la cultura Chalchihuites Rama Guadiana”. Tesis de Licenciatura en Arqueología, Escuela Nacional de Antropología e Historia, México.

Rincón, Sahira. 2013. "Imágenes femeninas en el Valle de Guadiana". En Historia de Durango. Época antigua, ed. José Luis Punzo y Marie-Areti Hers. Durango: IIH, UJED.

RodríGueZ, Nora. 2009. "El conjunto iconográfico Águila-Rombo-Serpiente en Chalchihuites Zacatecas. Un acercamiento a través de la analogía Wixarika (huichola)". Tesis de Licenciatura, Escuela Nacional de Antropología e Historia, México.

SANDOval, Cindy. 2011. "La aplicación de la petrografía en la caracterización y proveniencia de las cerámicas chalchihuiteñas de las ramas Guadiana y Súchil del sitio arqueológico La Ferrería en Durango, Dgo". Tesis de Licenciatura, Unidad Académica de Antropología, Universidad Autónoma de Zacatecas, Zacatecas. 
VIDAL, Cinthya Isabel. 2011. "El intercambio en el Noroccidente prehispánico. El intercambio entre la rama Guadiana de la tradición arqueológica Chalchihuites y la tradición Aztatlán, entre 600-1300 d.C”. Tesis de Licenciatura en Arqueología, Escuela Nacional de Antropología e Historia, México. 